\title{
Recent Optimization Highlights of the Georgywood Process
}

\author{
Jean-Pierre Barras, Bernadette Bourdin, and Fridtjof Schröder ${ }^{\star}$
}

\begin{abstract}
Alternative procedures to the industrial process by which Georgywood ${ }^{\circledR}$ is presently prepared on a multiton scale have been investigated. These give the crucial Homomyrcene precursor 5a and target compound 1 with greatly improved selectivities. Homomyrcene $\mathbf{5} \mathbf{a}$ was prepared with much better yield and selectivity by converting methylgeraniol 4 into an allylic carbonate, followed by a solvent-free palladium-catalyzed 1,4-elimination. In the final 1,5-diene cyclization, excellent selectivities were achieved by replacing Brønsted acid $\mathrm{H}_{3} \mathrm{PO}_{4}$ by $\mathrm{MeAlCl}_{2}$. This requires preparation, safety measures and an in-situ conversion of stoichiometric amounts of the pyrophoric Lewis acid. Recently, an in situ preparation of $\mathrm{MeAICl}_{2}$ from $\mathrm{AlMe}_{3}$ and its catalytic use became possible.
\end{abstract}

Keywords: 1,5-Diene cyclization · 1,4-Elimination · Georgywood $\cdot$ Homomyrcene $\cdot$ Methylaluminum dichloride

\section{Introduction}

Woody-amber smelling compounds are of considerable importance for the fragrance industry and the perfumer's palette [1]. The elegantwarm-woody, sweet-powdery smelling Georgywood ${ }^{\circledR}$ was discovered after an intensive search at Givaudan [2], which included an in-depth analysis of existing woody fragrance mixtures and the stereoselective synthesis of a variety of polysubstituted decalins [3]. A selective access to the olfactory most potent Georgywood isomer $\mathbf{1}$ is a challenge for the synthetic and process chemist. Thus, alternatives to the final cyclization step of the original patent have been developed at Givaudan [4]; a different access has been reported by Piancatelli [5] and both enantiomers of $\mathbf{1}$ were synthesized by Fráter [6] and Corey [7]. The following article reviews process improvements and alternatives to the crucial steps in the synthesis of 1 [2].

\section{Industrial Preparation at Givaudan}

Georgywood $^{\circledR}$ is presently produced according to Scheme 1. The established steps a and $\mathrm{c}$ of this procedure are the $\mathrm{MeMgCl}$ addition to citral $\mathbf{3}$, giving methylgeraniol 4, and the Diels-Alder-reaction of homomyrcene 5a, giving pseudo-Georgywood $\mathbf{6}$.

However, the dehydration step $\mathrm{b}$ and the acid-catalyzed 1,5-diene cyclization step d of the original process are not selective and give mixtures of $\mathbf{5 a b c}$ and $\mathbf{1 / 1} \mathbf{b}$ respectively [2]. To obtain cyclization precursor 6 with sufficient purity, the methylocimenes $\mathbf{5 b}$ have to be separated from the 5abc mixture by distillation. From the thus-obtained 5ac mixture fortunately only the more reactive 5a undergoes the subsequent Diels-Alder reaction. In the final acid-catalyzed cyclization step $\mathrm{d}$, concomitant pre-isomerization of the endocyclic double bond of $\mathbf{6}$ gives rise to a relatively odorless byproduct $\mathbf{1 b}$. For a more detailed explanation see [4] or [6b]. The consequences for the overall process economy are such that only $40 \%$ of methylgeraniol 3 is incorporated into pseudo-Georgywood 6 and that over $50 \%$ of the latter compound is converted into odorless isomer $\mathbf{1 b}$. Overall ca. $80 \%$ of precursor 4 is lost due to insufficient selectivities in steps $\mathrm{b}$ and $\mathrm{d}$.

\section{Selective Synthesis of Homomyrcene}

The palladium-catalyzed 1,4-elimination of allylic alcohol derivatives to the corresponding 1,3-dienes is a well-known synthetic transformation [8] which has been applied in the synthesis of fragrance precursors such as Myrcene [9] and Abienol [10].

This transformation was attempted on the allylic ester 7, where best results were obtained with the chelating ligands dppp or dppe. Monophosphine $\mathrm{PPh}_{3}$ and higher

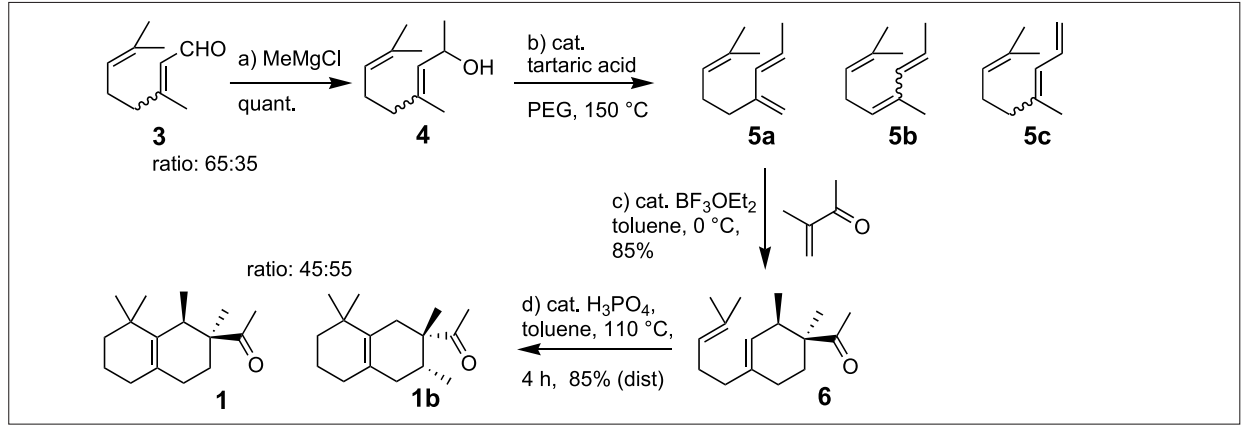

Scheme 1. 
diphosphine analogues such as dppb and dpppe gave again considerable amounts of 5c. Similar 5ab ratios were obtained using either the pure $E$ - or $Z$-isomers of 7 or even precursor 8. This indicates an equilibration of the different $\pi$-allyl-palladium intermediates, as studied in detail by Keinan et al. (on the same reaction with acetates of $\mathrm{Ge}$ raniol, Nerol and Linalool) [9a].

In order to reproduce the reaction shown in Scheme 2, the mixture had to be degassed before adding catalyst and ligand. Furthermore, $\mathrm{ca}$. $2 \%$ of a proton source such as water, butanol or unconverted alcohol $\mathbf{4}$ should be added to substrate 7 to start the palladiumcatalyzed elimination readily. For the role of water in the formation of $\operatorname{Pd}(0)$ from the $\mathrm{Pd}(\mathrm{II})$ pre-catalyst, see [11].

Adequate reaction rates and good selectivities towards $\mathbf{5 b}$ were only achieved with at least 1 equiv. of $\mathrm{NEt}_{3}$, which is known to scavenge acetic acid formed in this reaction [9][12]. More $\mathrm{NEt}_{3}$ (2 equiv.) accelerated the reaction, and degassed $\mathrm{NEt}_{3}$ could even be used as solvent instead of toluene. The presence of $\mathrm{NEt}_{3}$, however, did not suppress isomerization of $\mathbf{5 a}$ to the thermodynamically more stable $\mathbf{5 b}$ (Fig. 1), therefore the reaction had to be stopped at the maximum concentration of $\mathbf{5 a}$ to prevent any further erosion of the purity. Stoichiometric amounts of trialkylamines are problematic on an industrial scale.

These disadvantages could be circumvented by using carbonate 9 instead of acetate 7 as elimination precursor [13]. Allylic carbonates are decomposed to diene, EtOH and $\mathrm{CO}_{2}$ during Pd-catalyzed 1,4-elimination, acidic by-products are absent or can be neglected and the intermediary $\pi$-allylPd-OEt complex has strongly basic properties [14]. The 5ab mixture thus produced was indeed stable under the reaction conditions, terminal diene $\mathbf{5 c}$ was virtually absent $(<1 \%)$ and higher selectivities towards homomyrcene 5a were achieved. Due to this stability, the 5ab mixture could be distilled without prior quenching or aqueous work-up, directly from the catalyst. From the residue, which contains the partiallyoxidized diphosphine ligand, palladium can be easily recovered. Because the reaction was possible under solvent-free conditions, the catalyst load could be further decreased (Scheme 3).

A comparative study of different diphosphine ligands showed only marginal differences of the corresponding selectivities towards 5a, which were in the range of $68-78 \%$. These selectivities, however, were only reached with ligands having bite angles between $85-105^{\circ}$. Beyond this range, chelation is obviously not possible and the conversion becomes sluggish and incomplete. Within this range, best turnover rates and best selectivities were achieved with rigid

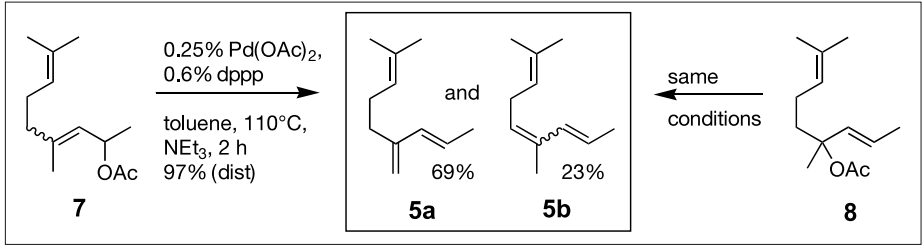

Scheme 2

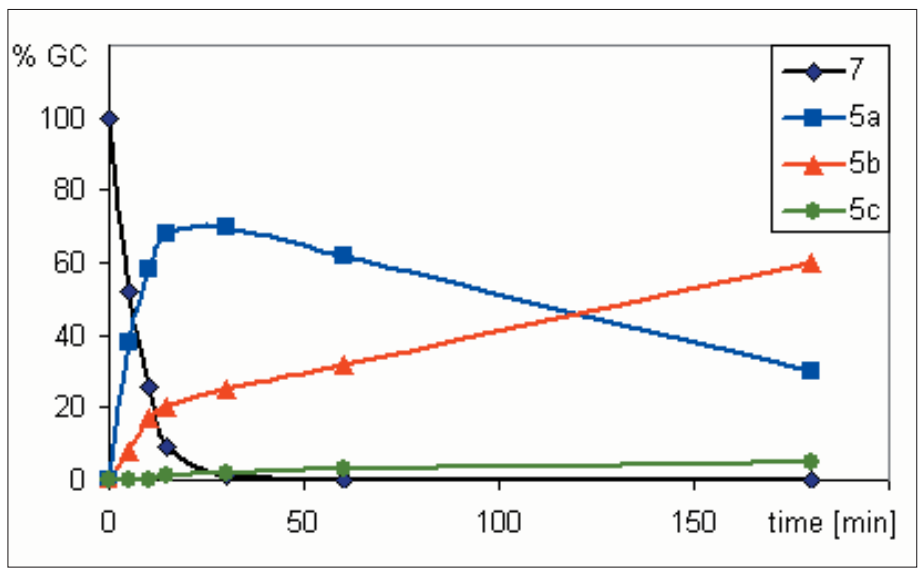

Fig. 1. Acetate 7, 1\% $\mathrm{Pd}(\mathrm{OAc})_{2}, 2 \%$ dppp, $2 \% \mathrm{H}_{2} \mathrm{O}$ and 1 equiv. $\mathrm{NEt}_{3}$ in degassed toluene at reflux. GC-conversion
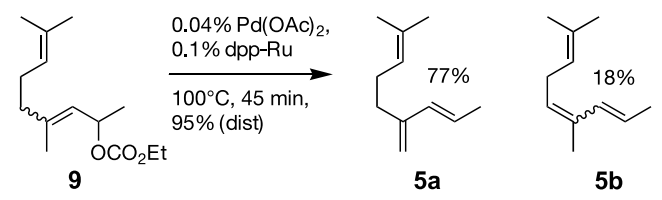

Scheme 3.

ligands having relatively large bite angles of $101-103^{\circ}$ (Table 1, Fig. 2).

Bite angle effects upon the selectivities of palladium-catalyzed allylic alkylation reactions have been thoroughly studied [16], originally by Trost under the term 'pocket effect' [17]. The natural bite angle $\beta_{n}$ has been defined as the preferred chelation angle determined only by ligand backbone constraints and not by metal valence angles [18]. In analogy to the bite angle dependence of the reductive elimination rate from bisalkylated diphosphine palladium complexes [19], $\beta_{n}$ should be also rate determining in the $\alpha$-elimination of $\mathrm{H}-\mathrm{Pd}-\mathrm{OR}$. Large rigid bite angles accelerate $\alpha$-elimination, bringing proton and leaving group in the H-Pd-OR elimination angle closer together.

The natural bite angles of dpppe and dpph were not available from the literature and were calculated with CERIOS II for square planar diphosphine-Pd(II)H(OEt) complexes. Because we found the $\beta_{n}$ of dppm, dppe, dppp and binap to be in good accordance with the ones from the literature (except dppb [16]), we are confident that the calculated bite angles of dpppe and dpph are appropriate for trend analysis.

If good selectivities are one side of the coin in process chemistry, then a catalytic reaction with inexpensive catalyst components and a high turnover is the other, because this has very often a more significant effect upon the overall cost reduction. Therefore, from all diphosphine ligands in Table 1, the relatively inexpensive dpppe ligand was chosen as the most appropriate one for further upscaling.

A short comment should be given on the preparation of carbonate 9 (Scheme 4), which had been initially prepared by the usual ethyl chloroformate/pyridine method. Among other alternatives, we should mention the simple and very efficient synthesis of mixed carbonates under methanolate catalysis [20]. Constant removal of ethanol drives the equilibrium to the right and most of the unconverted diethyl carbonate is recovered after complete conversion by distillation. Mixed carbonate $\mathbf{9}$ is obtained with sufficient purity as crude material or with excellent yield and purity after distillation (Scheme 4). 
Table 1. Influence of diphosphine natural bite angle $\beta_{n}$ on turnover rates and homomyrcene selectivities. $\operatorname{Pd}(\mathrm{OAc})_{2}$ added at $100{ }^{\circ} \mathrm{C}$ to carbonate 9 and ligand under nitrogen. Ligands which induced remarkably low catalyst concentrations, turnover rates and selectivities are marked green.

\begin{tabular}{|c|c|c|c|c|c|}
\hline Ligand a & $\begin{array}{l}\text { natural bite an- } \\
\quad \text { gle } \beta_{n}{ }^{b}\end{array}$ & $\begin{array}{l}\mathrm{Pd}(\mathrm{OAc})_{2} \\
\text { [conc.] }^{\mathrm{d}}\end{array}$ & $\begin{array}{l}\text { Time for } \\
\text { complete } \\
\text { conversion } \\
\text { (min) }\end{array}$ & $\begin{array}{l}\text { Turnover } \\
\text { rate [per } \\
\text { min] }\end{array}$ & $\begin{array}{c}\text { Selectivity } \\
\mathbf{5 a / 5 b}\end{array}$ \\
\hline dppm & $72^{\circ}$ & $0.2 \%$ & \multicolumn{3}{|c|}{ Sluggish conversion } \\
\hline dppe & $85^{\circ}$ & $0.2 \%$ & $120 \mathrm{~min}$ & 5 & $62: 24$ \\
\hline binap & $85^{\circ}$ & $0.2 \%$ & $25 \mathrm{~min}$ & 20 & $68: 27$ \\
\hline dppp & $91^{\circ}$ & $0.2 \%$ & $150 \mathrm{~min}$ & 5 & $78: 19$ \\
\hline dppb & $93^{\circ}(\text { calc) })^{c, f}$ & $0.2 \%$ & $20 \mathrm{~min}$ & 25 & $72: 22$ \\
\hline dpppe & $93^{\circ}(\mathrm{calc})^{\mathrm{c}}$ & $0.07 \%$ & $60 \mathrm{~min}$ & 25 & $74: 21$ \\
\hline dpph & $94^{\circ}(\mathrm{calc})^{\mathrm{c}}$ & $0.2 \%$ & $20 \mathrm{~min}$ & 25 & $68: 25$ \\
\hline dppf & $96^{\circ}$ & $0.07 \%$ & $15 \mathrm{~min}$ & 95 & $73: 21$ \\
\hline homoxanthphos & $102^{\circ}$ & $0.07 \%$ & $45 \mathrm{~min}$ & 30 & $76: 20$ \\
\hline Dpp-Ru & $101^{\circ} \mathrm{e}$ & $0.04 \%$ & $45 \mathrm{~min}$ & 60 & $77: 18$ \\
\hline DPE-phos & $103^{\circ}$ & $0.07 \%$ & $15 \mathrm{~min}$ & 95 & $76: 19$ \\
\hline xanthphos & $111^{\circ}$ & $0.14 \%$ & $>45 \min$ & $<10$ & $58: 16$ \\
\hline DBF-phos & $138^{\circ}$ & $0.14 \%$ & $>45 \mathrm{~min}$ & $<10$ & 49:25 \\
\hline
\end{tabular}

a) $\mathrm{Pd}(\mathrm{OAc}) /$ ligand $=1: 2.5$. For abbreviations of the ligands see Fluka-catalogue 2005/2006, Fig. 2 or [16]. b) Natural bite angles $\beta_{\mathrm{n}}$ were taken from [16]. c) Calculated with CERIOS II for square planar diphosphine- $\mathrm{Pd}(\mathrm{I}) \mathrm{H}(\mathrm{OEt})$ complexes. d) Lowest $\mathrm{Pd}(\mathrm{OAc})_{2}$ concentration, where the reaction was reproducible. e) P-Ru-P angle (X-ray), [15] f) A $\beta_{n}$ of $98^{\circ}$ has been reported for this ligand [16].

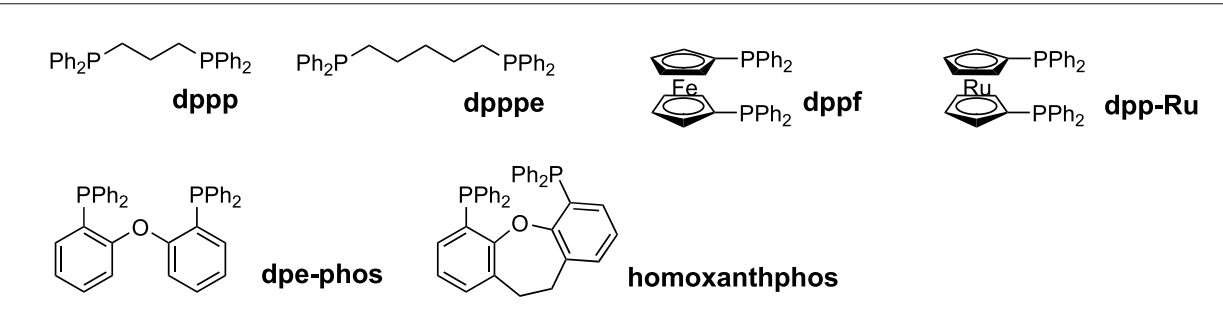

Fig. 2.

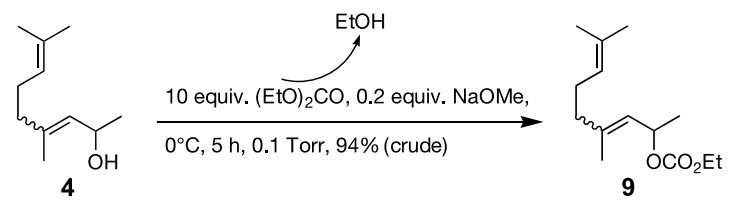

Scheme 4

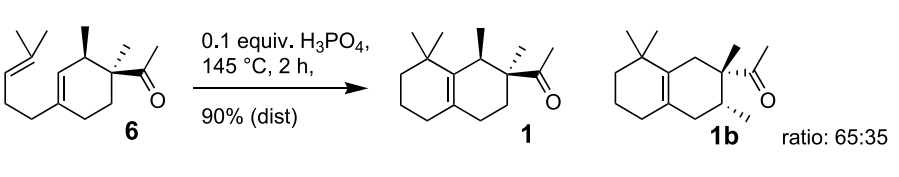

Scheme 5

\section{Synthesis of Georgywood Promoted by $M X_{n}$ Type Lewis Acids}

Compared with the actual process (Scheme 1) [2], selectivities of up to 65:35 in favor of Georgywood 1 were achieved by running the phosphoric acid-catalyzed cyclization of $\mathbf{6}$ at higher temperatures, either in xylene or even solvent-free (Scheme 5). The olfactory quality of the product, however, was insufficient, due to the more drastic reaction conditions.

Because pre-isomerization of the endocyclic double bond of $\mathbf{6}$ was an inherent problem with all Brønsted acids tested [4] a variety of Lewis acids was screened to avoid this side reaction (Table 2). For Lewis acidpromoted biomimetic cyclization reactions of polyprenoids, see [21].

Indeed, with some active and strong $\mathrm{MX}_{\mathrm{n}}$ type Lewis acids, pre-isomerization and formation of byproduct $\mathbf{1 b}$ was now completely suppressed! For this purpose more than 1 equiv. of these Lewis acids in non-etheral solvents had to be employed to overrule complexation with the carbonyl group. The post-isomerization equilibrium 1:10:11, however, was a new phenomenon, which was influenced by several factors, e.g. the Lewis acid employed and work-up conditions. Because the $\mathrm{C}-\mathrm{C}$ connectivity of $\mathbf{1 0}$ and $\mathbf{1 1}$ is identical to the one of Georgywood 1, the crude mixture could be converted to the desired $\beta$-isomer 1 under acidic conditions. This process was seriously considered for upscaling and development in the plant, but the overall yield of 1 from 6 (only $40 \%$ overall according to Scheme 6) could not be further optimized. Side-reactions such as dimerization and polymerization under these conditions are due to the reactivity of enol ether $\mathbf{1 0}$ [4].

\section{Selective Synthesis of Georgywood Promoted by $\mathrm{MeAICl}_{2}$}

In order to soften the aggressiveness of the above-mentioned $\mathrm{MX}_{\mathrm{n}}$ type Lewis acids and to prevent post-isomerization, organoaluminum compounds $\mathrm{R}_{\mathrm{n}} \mathrm{AlX}_{\mathrm{m}}$ were screened systematically. Finally, superior yields and selectivities towards 1 were obtained in the presence of methylaluminum dichloride (Scheme 7). Byproduct 1b was not produced and post-isomerization did not occur. $\mathrm{MeAlCl}_{2}$ is the first alkyl homologue of $\mathrm{AlCl}_{3}$. Already the next higher homologue $\mathrm{EtAlCl}_{2}$ needed a higher cyclization temperature and gave lower yields due to concomitant polymerization [4].

The first synthesis of essentially pure Georgywood 1 directly from precursor 6 was a very convincing milestone in our research program (Fig. 3). The selectivity towards 1 was far superior to that achieved 
Table 2: Classification of type $\mathrm{MX}_{\mathrm{n}}$ Lewis Acids $(\mathrm{X}=\mathrm{F}, \mathrm{Cl}, \mathrm{Br}$ ) by reactivity and selectivity towards $\beta$-isomer 1, enol ether 10 and $\gamma$-isomer 11 (Scheme 6). Lewis acids giving predominantly isomers of this mixture are marked green. Lewis acids with strong $\beta$-Georgywood 1 preference are marked bold. Lewis Acids marked in italics gave predominantly isomer $\mathbf{1 b}$. Lewis acids marked blue were ineffective. All Lewis acids were employed with 1.5 equiv. in toluene, xylene, cyclohexane, dichloromethane or nitroalkanes between $0{ }^{\circ} \mathrm{C}$ and $25^{\circ} \mathrm{C}$, except $\mathrm{BBr}_{3}$ at $-50{ }^{\circ} \mathrm{C}$.

$\begin{array}{lllll}\mathrm{BBr}_{3} & > & \mathrm{BCl}_{3} & \geq & \mathrm{BF}_{3} \\ \mathrm{AlBr}_{3} & \geq & \mathrm{AlCl}_{3} & >> & \mathrm{AlF}_{3} \\ \mathrm{ZrCl}_{4} & \geq & \mathrm{ZrBr}_{4} & > & \mathrm{ZrF}_{4} \\ \mathrm{TiCl}_{4} & \geq & \mathrm{TiBr}_{4} & >> & \mathrm{TiF}_{4} \\ \mathrm{FeCl}_{3} & > & \mathrm{FeBr}_{3} & >> & \mathrm{FeF}_{3} \\ \mathrm{SnCl}_{4} & > & \mathrm{SnBr}_{4} & \approx & \mathrm{SnF}_{4} \\ \mathrm{ZnCl}_{2} & > & \mathrm{ZnBr}_{2} & >> & \mathrm{ZnF}_{2}\end{array}$

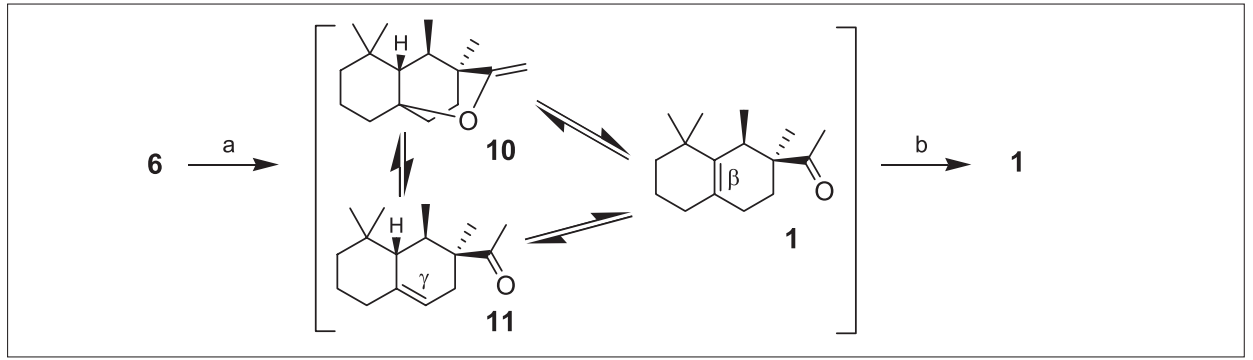

Scheme 6. a) $>1$ equiv. $M X_{n}$, between $-50^{\circ} \mathrm{C}$ and $25^{\circ} \mathrm{C}$, several $\mathrm{h}, 40-60 \%$ (dist). $M \mathrm{X}_{\mathrm{n}}=\mathrm{BBr}_{3}, \mathrm{BCl} 3$, gaseous $\mathrm{BF}_{3}, \mathrm{AlBr}_{3}, \mathrm{AlCl}_{3}, \mathrm{ZrCl}_{4}, \mathrm{TiCl}_{4}$ or $\mathrm{TiBr}_{4}$ in toluene, $\mathrm{CH}_{2} \mathrm{Cl}_{2}$ or nitropropane. b) 0.2 equiv. pTSA, toluene, $100^{\circ} \mathrm{C}, 4 \mathrm{~h}, 72 \%$ (dist).

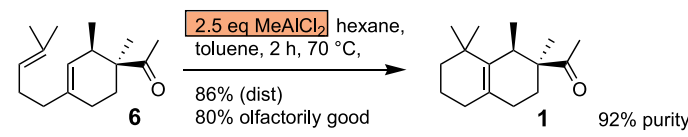

Scheme 7.

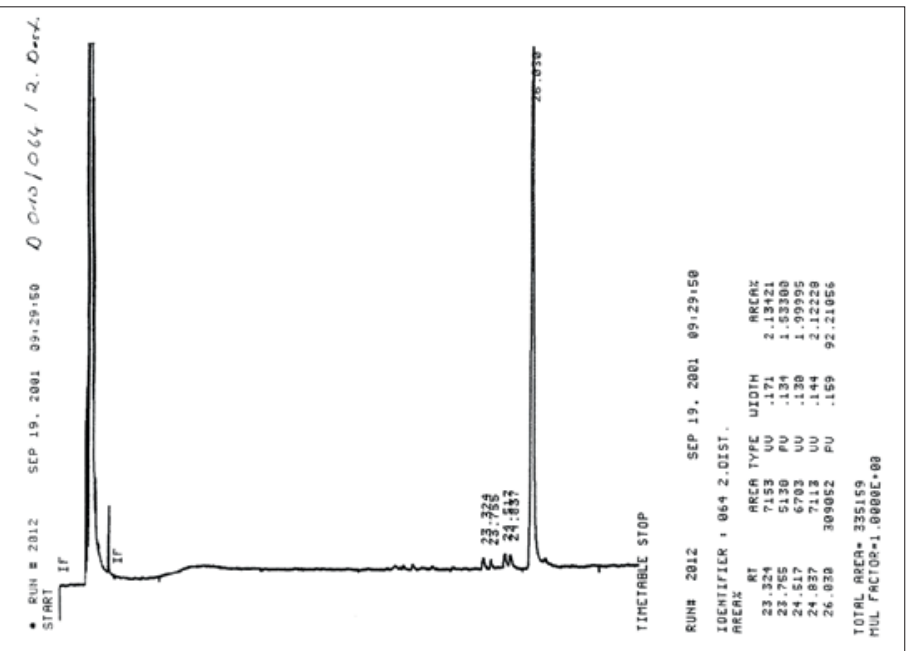

Fig. 3. GC of Georgywood $\mathbf{1}$ as obtained from precursor $\mathbf{6}$ in the presence of 2.5 equiv. $\mathrm{MeAlCl}_{2}$

Table 3.

- $\mathrm{MeAlCl}_{2}$ is pyrophoric.

- Although small amounts of diluted $\mathrm{MeAICl}_{2}$ are commercially available for laboratory use, the transportation of larger amounts of $\mathrm{MeAlCl}_{2}$ is problematic due to the melting point of the neat substance $\left(70^{\circ} \mathrm{C}\right)$ or its tendency to precipitate in organic solvents.

- The quench of the reaction mixture was highly exothermic.

- 2.5 equiv. of gaseous methane was generated during quenching.

- 2.5 equiv. of $\mathrm{Al}(\mathrm{OH})_{3}$ wastes had to be discarded after work-up. with any other reagent. The new quality was preferred over the benchmark because its better olfactory profile. Because the content of the olfactorily active Georgywood isomer $\mathbf{1}$ is considerably increased, the new quality is $2-3$ times stronger. This means that less Georgywood is required in perfumery compositions to create the same olfactory effect.

However, before a $\mathrm{MeAlCl}_{2}$ promoted reaction could be further developed, some inherent problems of this organoaluminum reagent had to be addressed (Table 3 ).

Having solved most of these critical issues, $\mathrm{MeAlCl}_{2}$ was finally prepared via the sequence $\mathrm{Al} \rightarrow \mathrm{Me}_{3} \mathrm{Al}_{2} \mathrm{Cl}_{3} \rightarrow \mathrm{MeAl}$ $\mathrm{Cl}_{2}$ (Scheme 8). Preparation, handling and analysis of these organoaluminum compounds required some unusual means:

- Activation of aluminum grit: Although several procedures for the activation of aluminum have been reported [22], in our hands a fast and reproducible formation of the intermediate sesquichloride $\mathrm{Me}_{3} \mathrm{Al}_{2} \mathrm{Cl}_{3}$ was only possible after activation with catalytic amounts of crude $\mathrm{Me}_{3} \mathrm{Al}_{2} \mathrm{I}_{3}$ [23], which was sprinkled as such over the aluminum grit.

- Pressure-free sesquichloride formation: Because under-pressure explosions have been reported [24] $\mathrm{Me}_{3} \mathrm{Al}_{2} \mathrm{Cl}_{3}$ was prepared under a chloromethane atmosphere. In combination with $\mathrm{Me}_{3} \mathrm{Al}_{2} \mathrm{I}_{3}$ activation, the reaction was perfectly controllable and the same technical equipment was used as employed for the formation of Grignard reagents in the plant.

- Gas-solid reaction, abrasion, subsequent addition of $\mathrm{AlCl}_{3}$ : Abrasion was not as problematic as expected, because the aluminum grit liquefied rapidly under the $\mathrm{MeCl}$ atmosphere without additional stirring. The stirrer was started, when the $\mathrm{Me}_{3} \mathrm{Al}_{2} \mathrm{Cl}_{3}$ liquid thus formed could be used as solvent for the remaining aluminum grit. Another option was a stirring blade with a short diameter, to stir the aluminum only locally right from the beginning. Subsequent $\mathrm{AlCl}_{3}$ addition was performed continuously over a nitrogen-flushed conveyor screw.

- Analysis: Complete formation of $\mathrm{Me}_{3} \mathrm{Al}_{2} \mathrm{Cl}_{3}$ was roughly estimated measuring the reaction volume. The quality of the prepared $\mathrm{MeAlCl}_{2}$ was checked by rapid cooling under $70{ }^{\circ} \mathrm{C}$ (solidification) or distillation $\left(\mathrm{bp}=155^{\circ} \mathrm{C}\right)$. The distillate crystallizes in long white needles. The formation of both compounds was also conveniently followed by ${ }^{27}$ Al-NMR [25].

- Quench, purification and wastes: Quenching the reaction mixture stepwise, first with ethanol, then with $2 \mathrm{M}$ $\mathrm{HCl}$ smoothed the exotherm of the quench reaction. The dumping of the 


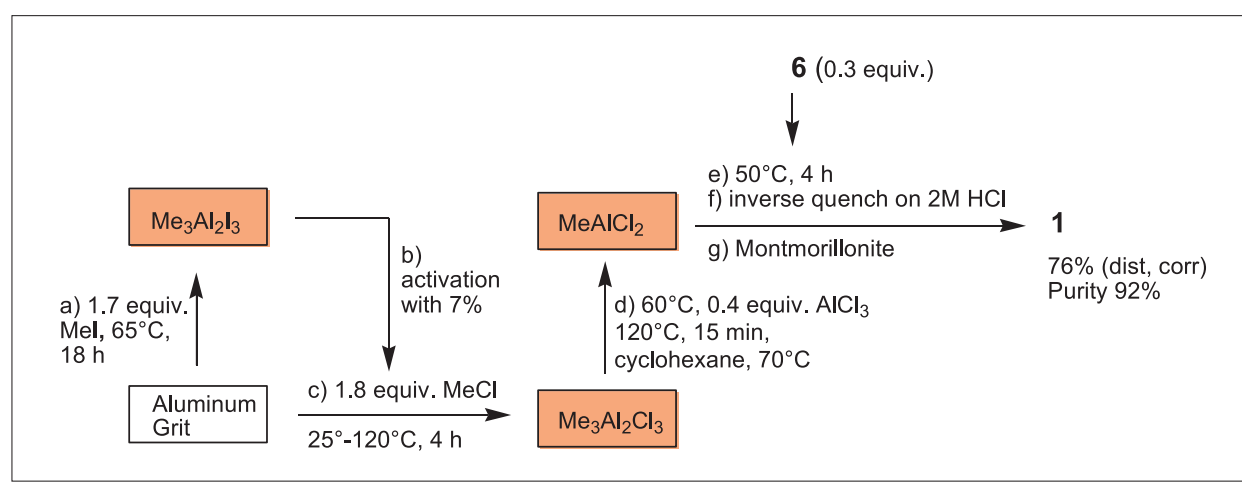

Scheme 8.

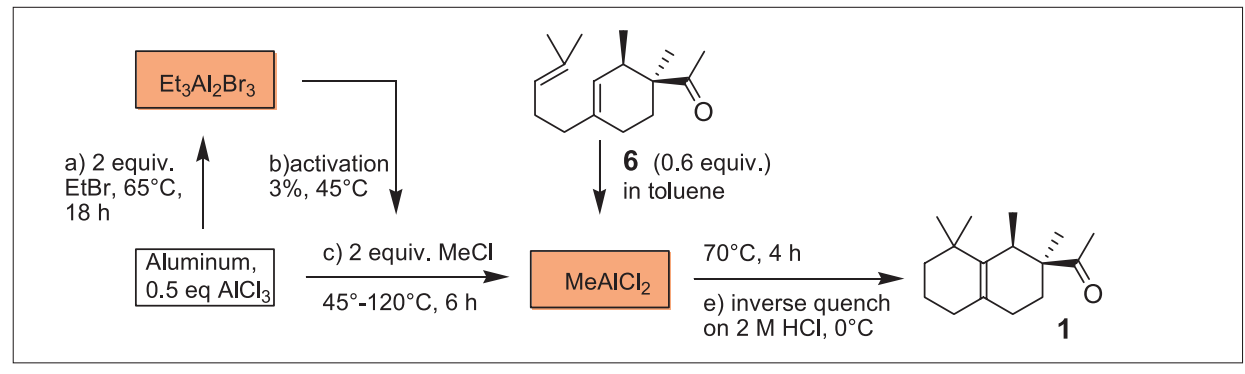

Scheme 9

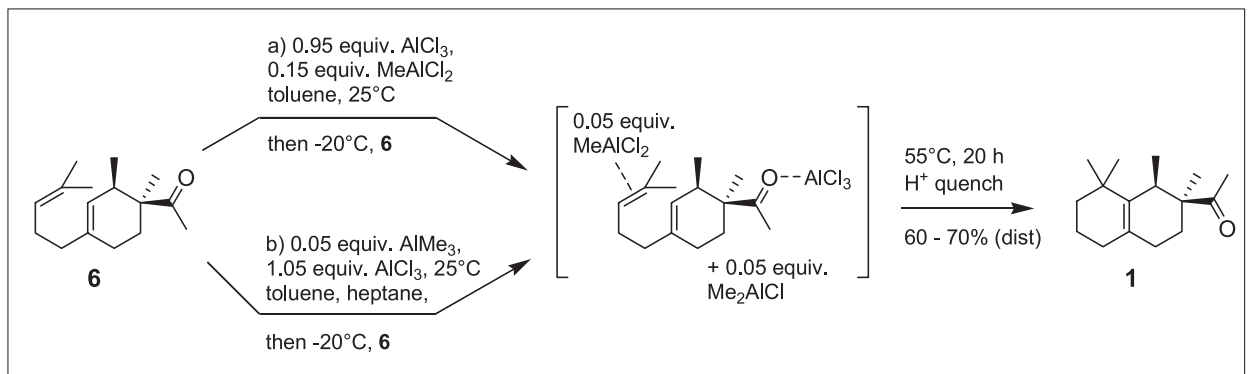

Scheme 10. Cyclization of precursor 6 with catalytic amounts of $\mathrm{MeAICl}$ or $\mathrm{AlMe}_{3}$. Yields corrected by purity.

$\mathrm{Al}(\mathrm{OH})_{3}$ wastes had no significant impact on the material costs. Due to the use of activation reagent $\mathrm{Me}_{3} \mathrm{Al}_{2} \mathrm{I}_{3}$, however, the Georgywood 1 thus produced was deeply yellow, nearly black. Fortunately, treatment of the crude product with montmorillonite [26] furnished colorless and olfactorily good material with $76 \%$ yield and excellent GC purity after distillation, comparable to the one obtained from commercially-available $\mathrm{MeAlCl}_{2}$.

Further improvements were achieved on a larger scale (Scheme 9). The activation reagent $\mathrm{Me}_{3} \mathrm{Al}_{2} \mathrm{Br}_{3}$, although slightly less active than $\mathrm{Me}_{3} \mathrm{Al}_{2} \mathrm{I}_{3}$, allowed an overall iodide-free process with the advantage that the montmorillonite decoloration step was no longer necessary. Another improvement was the preparation of $\mathrm{MeAlCl}_{2}$ directly from an aluminum grit/ $\mathrm{AlCl}_{3}$ mixture, which made the subsequent addition of solid aluminum chloride obsolete [4].

\section{Cyclization with Catalytic Amounts of $\mathrm{MeAICl}_{2}$}

At this point, the critical eye of the process chemist will certainly have noticed some remaining shortcomings of the abovementioned $\mathrm{MeAlCl}_{2}$ process (Scheme 9). Due to detailed studies on the mechanism of the cyclization reaction, which were carried out in parallel [4], we arrived at a new potential process, in which catalytic amounts of $\mathrm{MeAlCl}_{2}$ can be used (path a), provided the carbonyl group of $\mathbf{6}$ is blocked with $\mathrm{AlCl}_{3}$ (Scheme 10).

Although the yield of the catalytic version is slightly lower, the process advantages are obvious: less pyrophoric reagent, less exothermic quench, less aluminum waste and less generation of gaseous methane. In the $\mathrm{AlMe}_{3}$ catalyzed version (b) the catalyst $\mathrm{MeAlCl}{ }_{2}$ is generated in situ from pre-catalyst $\mathrm{AlMe}_{3}$ in the presence of excess $\mathrm{AlCl}_{3}$. Commercial availability and transport of $\mathrm{AlMe}_{3}$ (40\% in toluene) is much more advanced than those of $\mathrm{MeAlCl}_{2}$ (Scheme10).

\section{Conclusion}

Palladium-catalyzed 1,4-elimination of allylic carbonate 9 gave homomyrcene 5a with hitherto unattained 5ab selectivities of up to 78:22. The product mixture thus obtained is stable under the reaction conditions and the unwanted diene $\mathbf{5 c}$ was formed in negligible amounts only. Distillative separation of the 5ab mixture gave homomyrcene 5a with hitherto unattained purities of $>95 \%$. Due to process efficiency considerations the catalyst system chosen for upscaling was not the most selective, but one with a better turnover rate and a relatively low material cost impact $\left(\mathrm{Pd}(\mathrm{OAc})_{2} /\right.$ dpppe).

$\mathrm{MeAlCl}_{2}$ promoted cyclization of precursor 6 gave $\beta$-Georgywood 1 directly with excellent yield and purity. The fullydeveloped process starts from aluminum, gaseous $\mathrm{MeCl}$ and $\mathrm{AlCl}_{3}$ and allows the preparation of Georgywood 1 via the in situ formed $\mathrm{MeAlCl}_{2}$ in one vessel. A catalytic variant of this cyclization using pre-catalyst $\mathrm{AlMe}_{3}$ and stoichiometric amounts of $\mathrm{AlCl}_{3}$ is presently the subject of upscaling and olfactory evaluation.

\section{Acknowledgements}

We would like to thank our colleagues at Givaudan for their analytical and experimental help and for always interesting discussions. Valuable suggestions were also obtained from external consultants

Received: June 20, 2006

[1] a) M. Gautschi, J.A. Bajgrowicz, P. Kraft, Chimia 2001, 55, 379-387; b) P. Kraft, J.A. Bajgrowicz, C. Denis, G. Fráter, Angew. Chem., Int. Ed. 2000, 39, 2980-3010; c) G. Fráter, J.A. Bajgrowicz, P. Kraft, Tetrahedron 1998, 54, 7633-7703.

[2] J.A. Bajgrowicz, A. Bringhen, G. Fráter, U. Müller, EP 0743297, priority 16.5 .1995 to Givaudan; Chem. Abstr. 126, 103856h.

[3] F. Etzweiler, D. Helmlinger, C. Nussbaumer, M. Pesaro, EP 0464357, priority 2.6.1990 to Givaudan; Chem. Abstr. 116, 194638w. See also C. Nussbaumer, G. Fráter, P. Kraft, Helv. Chim. Acta 1999 , 82, 1016-1024.

[4] a) F. Schröder, 11th International Conference of Organic Process Research \& Development, Barcelona, Spain, 25-28 April 2005; b) F. Schröder, XVI. Fechem Conference on Organometallic Chemistry, Budapest, Hungary, 3-8 September 2005; c) J.-P. Barras, F. Schröder, WO 2005016938, priority: 18.8 .2003 to $\mathrm{Gi}-$ vaudan; Chem. Abstr. 142, 219409z.

[5] M. Bella, M. Cianflone, G. Montemurro, G. Passacantilli, G. Piancatelli, Tetrahedron 2004, 60, 4821-4827.

[6] a) G. Fráter, U. Müller, C. Nussbaumer Book of Abstracts, 213th ACS National 
Meeting, San Francisco, April 13-17, 1997, Publisher: American Chemical Society, Washington D.C.; b) G. Fráter, U. Müller, F. Schröder, Tetrahedron: Asymmetry 2004, 15, 3967-3972.

[7] S. Hong, E.J. Corey, J. Am. Chem. Soc. 2006, 128, 1346-1352.

[8] a) I. Shimizu, 'Handbook of Organopalladium Chemistry for Organic Synthesis', Ed.: E.-I. Negishi, John Wiley \& Sons, Inc., New York, 2002, 2, 1981-1994; b) J. Tsuji, 'Palladium Reagents and Catalysts', John Wiley \& Sons, Ltd., Chichester 1995, 356-363.

[9] a) E. Keinan, S. Kumar, V. Dangur, J. Vaya, J. Am. Chem. Soc. 1994, 116, 1115111152; b) A. Carpita, F. Bonaccorsi, R. Rossi, Tetrahedron Lett. 1984, 25, 51935196; c) H. Matsushita, E.-I. Negishi, J. Org. Chem. 1982, 47, 4161-4165; d) J. Tsuji, T. Yamakawa, M. Kaito, T. Mandai, Tetrahedron Lett. 1978, 24, 2075-2078.

[10] I.C. Coste-Manière, J.P. Zahra, B. Waegell, Tetrahedron Lett. 1988, 29, 1017-1020.

[11] a) C. Amatore, E. Carré, A. Jutand, M.A. M'Barki, Organometallics 1995, 14 , 1818-1826; b) F. Ozawa, A. Kubo, T. Hayashi, Chem. Lett. 1992, 2177-2180.

[12] B.M. Trost, T.R. Verhoeven, J.M. Fortunak, Tetrahedron Lett. 1979, 2301-2304.

[13] We are aware of other possibilities, which could have resulted in a selective synthesis of Homomyrcene 5a, e.g. the Pd-catalyzed elimination of the $Z$-isomer of $\mathbf{7}$ in the presence of 1 equiv. (!) propargylzinc bromide [9c] or 1 equiv. of allylstannane (!) [9a]. For impressive selectivities using dialkylamines (!) instead of an acetates as leaving groups see a) H. Kumobayashi, S. Mitsuhashi, S. Akutagawa, S. Ohtsuka, Chem. Lett. 1986, 157-160; b) A.J. Chalk, V. Wertheimer, S.A. Magennis, J. Mol. Cat. 1983, 19, 189-200.

[14] a) J.M. Takacs, E.C. Lawson, F. Clement, J. Am. Chem. Soc. 1997, 119, 5956-5957; b) T. Takahashi, N. Nakagawa, T. Minoshima, H. Yamada, J. Tsuji, Tetrahedron Lett. 1990, 31, 4333-4336; c) J. Tsuji, I. Shimizu, I. Minami, Y. Ohashi, T. Sugiura, K. Takahashi, J. Org. Chem. 1985, 50, 1523-1529.

[15] S. Li, B. Wei, P.N.M. Low, H. Kee Lee, T.S. Andy Hor, F. Xue, T.C.W. Mak, J. Chem. Soc., Dalton Trans. 1997, 1281-1288.
[16] a) P.W.N.M. Leeuwen, P.C.J. Kramer, J.N.H. Reek, P. Dierkes, Chem. Rev. 2000, 100, 2741-2769; b) R.J. Haaren, H. Oevering, B.B. Coussens, G.P.F. Strijdonck, J.N.H. Reek, P.C.J. Kramer, P.W.N.M Leeuwen, Eur. J. Inorg. Chem. 1999, 1237-1241; c) M. Kranenburg, P.C.J. Kramer, P.W.N.M. Leeuwen, Eur. J. Inorg. Chem. 1998, 25-27.

[17] a) B.M. Trost, D.L. Van Vranken, C. Bingel, J. Am. Chem. Soc. 1992, 114, 9327; b) B.M. Trost, D.J. Murphy, Organometallics 1985, 4, 1143-1145.

[18] This definition is independent of any electronic preference imposed by the metal center and is based solely on steric considerations. C.P. Casey, G.T. Whiteker, Israel J. Chem. 1990, 30, 299-304.

[19] J.M. Brown, P.J. Guiry, Inorganica Chimica Acta 1994, 220, 249-259.

[20] P.A. Christenson, EP 0659732, priority 22.12.1993 to Givaudan-Roure S.A.; Chem. Abstr. 123, 112459.

[21] a) R.A. Yoder, J.N. Johnston, Chem. Rev 2005, 105, 4730-4756; b) M.C. De la Torre, M.A. Sierra, Angew. Chem. Int. Ed. 2004, 43, 160-181; c) L.F. Tietze, U. Beifuss, Angew. Chem. Int. Ed. Eng. 1993, 32, 131-163; d) N. Gnonlonfoun, Bull. Chem. Soc. Fr. 1988, 862-869; e) P.A. Bartlett, in 'Asymmetric Synthesis', Ed.: J.D. Morrison, Acad. Press: New York, 1982; Vol. III, pp 341-409; f) W.S. Johnson, Angew. Chem. Int. Ed. Eng. 1976, 15, 9-17.

[22] H. Lehmkuhl, K. Ziegler, in 'HoubenWeyl, Methoden der organischen Chemie', 1970, Vol. 13/4, pp 51-55 and pp 59-78.

[23] A.V. Grosse, J.M. Mavity, J. Org. Chem. 1940, 5, 106-121.

[24] a) G.P. van der Kelen, Bull. Soc. Chim. Belg. 1956, 65, 343-349; b) V.F. Hnizda, C.A. Kraus, J. Am. Chem. Soc. 1938, 60, 2276.

[25] R.K. Harris, B.E.Mann, 'NMR and the Periodic Table', Academic Press, 1978, p 279.

[26] See http://www.albmolecular.com/features/ telkreps/ vol01/no02; R. Jason, Albany Molecular Research, Inc. 1997. 